\title{
Takaful Retirement Annuity Plan in Malaysia: An Investigation on Consumers' Perceived Value and Knowledge Mediated by Attitude
}

\author{
${ }^{1}$ Mohammad Niaz Morshed, ${ }^{2}$ Sardar Md Humayun Kabir*, \\ ${ }^{3}$ Fadhilah Abdullah Asuhaimi, ${ }^{4}$ Md Muhibbullah \\ ${ }^{1,2,3,4}$ International Islamic University Malaysia
}

\begin{abstract}
Annuities are being treated as a backup financial strategy throughout the age of retirement and a way of reducing the long-term risk of a person's old age. Takaful markets in Malaysia have wanted to advance an annuity plan backed by Islamic Shari'ah and similar to the purpose pursued by an insurance company, but failed to do so after initiation in early 1999 . The objective of this study was to investigate the relationship among consumers' decision to take Takaful retirement annuity plan and their perceived value, knowledge mediated by attitude. Quantitative research has been conducted by a structured questionnaire survey on participants' attitude, perceived value and knowledge of Takaful retirement annuity plan. The sample $(n=121)$ for this study consisted of the employees working in different functional units of the International Islamic University Malaysia located in the metropolitan capital (Kuala Lumpur and Selangor) area of Malaysia. The findings from this study unveiled that the attitude and perceived value of the participants had a significant positive relationship with their decisions to take Takaful retirement annuity plan. But no direct connection has been found between knowledge and choices on Takaful retirement annuity plan. The significant practical implication of this study will be the Takaful operators, their customers, and researchers.
\end{abstract}

Keywords: Takaful retirement annuity plan, Malaysia, attitude, perceived value,

\section{Introduction}

People are disposed to hazards and bad lucks. Cautionary measures must take to keep safe individuals from unexpected dangers and bad lucks. One of the protection tools is that try to find safety through Takaful plan (Htay et al., 2012). There are mainly two kinds of Takaful plan products: general Takaful and Family Takaful products. This paper will focus on one part of the family Takaful product, which is Takaful retirement annuity plan. In1985, Takaful was launched in Malaysia, and its' penetration amount is minimal, that was approximately $7.9 \%$ in 2008 (Mohamed \& Alhabshi, 2015).

Annuities are seen as a backup financial strategy throughout the age of retirement and a way of reducing the long-term risk of a person's old age. To secure regular payments throughout the older period, annuitants try to ensure that the liquid amounts in return against a certain amount of fees till he/she deceases. Also, it may embrace conditions like death allowance or an amalgamation of permanent and flexible annuities for protection facing the lack of investment in the annuity trust (Soualhi, 2017). Takaful markets like Malaysia's have wanted to advance an annuity policy which would be backed by Shari'ah principles and similar purpose pursued by an insurance company, which means assuring a series of reimbursement at the age of retirement through accessible provisions to safe death facilities. Malaysia initiated Shari'ah compliance annuity policy called Employment Provident Fund (EPF) Takaful Annuity Scheme (SATK) in 1999 (Yusof et al., 2011).

Even though retirement annuity plan has been broadly used by business and personnel, it was withdrawn in 2002 because of valuing and risk-based capital (RBC) necessities, amongst other causes (Ismail, 2017). Moreover, the Takaful market is almost closed with policyholders who prefer to stay in the program, which creates a few annuitants in Malaysia. Furthermore, as a financial sector controller, the Central Bank of Malaysia is quite resistant with the sanction of the Takaful industry, which obligate with the high-capital 
prerequisite after the inception of the Risk-Based Capital (RBC) prerequisite in 2007 (Asmuni \& Purcal,2018).

Apart from the issues above, Takaful retirement annuity products are mainly nonexistent because of specific problems. Banks usually subscribe to a considerable amount of Sukuks (Islamic Bond), so there is a deficiency of Sukuks for Takaful Industry. The secondary Sukuk market is mostly non-liquid and costly. Besides, since the period of the Sukuk prevails in the market is short and medium, there is an issue with the presence of long term Sukuk (for example 20-30 years maturity). Also, there is a problem with longevity risk accumulation in the Takaful trust, as the participants will make donations and withdraw routine revenues from the pool. Also, if the annuity installments taken by the policy-holder surpass the early contribution paid-out, there is a possibility of riba problem (Soualhi, 2017).

Retirement is a vital reality for everyone. It is a solid plan for everyone at post-retirement if one wishes to maintain his/her financial independence and uphold a comfortable standard of living. In the case of Malaysia, there are many retirements plan like EFP (Employees Provident Fund) exist in the annuity market, which is not Shari'ah-compliant. Muslim people cannot possess those conventional retirement annuities to plan due to the Shari'ah issues. Since Malaysia is a Muslim Majority country; therefore, a Takaful retirement annuity plan is very much needed to remove the financial hardship at post-retirement for Muslim retires. At present, there is no Takaful retirement plan for Muslim retirees. Previously, there was a Takaful retirement annuity plan in Malaysia annuity market a few years back, but it was withdrawn.

The research objectives are taken in consideration for the study are (i) to know the relationship between the perceived value of people and attitude of people towards Takaful Retirement Annuity Plan; (ii) to see the relationship between the Knowledge of people and attitude of people towards Takaful Retirement Annuity Plan; (iii) to know the relationship between the perceived value of people and Takaful Retirement Annuity Plan; (iv) to know the relationship between the Knowledge of people and Takaful Retirement Annuity Plan; (v) to know the relationship between the Attitude of people and Takaful Retirement Annuity Plan.

A primary literature review on Takaful retirement annuity plan has shown that there is not much literature available in this area of research. Therefore, it is hoped that this paper will be a contribution to the writing and will be part of further research on this subject. The study also will help the Takaful service provider to expand Takaful retirement annuity plan which has been unused for a few years as well as it will contribute most to retirees who do not have sufficient attitude and knowledge on this Takaful product which would be needed during their retirement age

\section{Literature Review}

Takaful is derived from an Arabic word for collective security; in this way, a cluster of contributors agreed to mutually support each other for the losses resulting from the mentioned risks. In a Takaful plan, contributors donate the money as a Tabarru' assurance to a mutual fund to be used jointly to support associates against a specific loss. In some instances, the burden of a mutually paid instalment is like conventional mutual insurance. A distinctive Takaful comprises of a two-sided structure which is a hybrid of a business method of the corporation which is Takaful operator (TO) - though, in principle, it may be a clean joint structure (Jaffer et al., 2010).

Ali et al. (2018) proposed wakālah and hibah mu'allaqah as the basic ideas for offering a Shari'ah-agreeable retirement annuity plan. The wakālah model is utilized to control and contribute the annuity store until the retirement. This will be trailed by hibah mu'allaqah, whereby the commitments and the benefits emerging from the venture of the annuity store will be given to the tabarru' (gift) reserve to begin the annuitization arrange. The tabarru' finance is utilized to make the flood of installments during retirement (for example retirement payout) and to pay the passing advantages (for example passing compensation out). Also, Takaful companies are continuously looking for advancement in its efforts to increase attractiveness and meet Shari'ah obligations, besides behaving towards the clients and Takaful Operators (TO) equally, which is the objective of Shari'ah (Ali et al., 2018, Sabirzyanov \& Hashim, 2015).

Soualhi (2017) found that Takaful retirement annuity plan is needed to diversify through different portfolios of securities instead of just using Sukuk as an investment tool. Moreover, Mohamed \& Alhabshi (2015) have suggested that to improve the Takaful market penetration; the industry needs to advance the supply networks 
and marketing policies as well as need to develop the products which fit clients' perceived value following the various segments of the community.

While the Middle-Eastern and African region of the world bragged the most numbers of Takaful operators, however, the South-East Asian nations, notably Malaysia, Indonesia, Brunei have been in for more than 22 years, and the financial institutions representing this sector has been resilient and stable in their growth contributing to personal and national development (Rahman et al., 2004). It is predicted that the Malaysian Takaful market is set to grow at an average rate of $19.6 \%$ annually, and this is much higher than the conventional insurance market at $8.4 \%$. The combined Takaful contributions (premiums) for both family and general Takaful over the last nine years (1997-2005) have been impressive, contributing from $0.7 \%$ to 1.2 of Gross National Products, (2001-2006) respectively, while total Takaful fund assets stand at $1.6 \%$ to $4.8 \%$ of GNP for the same period. Its percentage of total assets in the insurance and takaful industry has grown too. The demand for Takaful product in Malaysia is relatively high due to the religious factor. The longevity of the Malaysian people has increased. Therefore, post-retirement financial stability is the most crucial element to retire. Thus, the perceived values of Takaful annuity retirement plan in Malaysia most demandable instrument for Takaful operator.

Attitude refers to understanding (or misunderstanding), distinguishing and contains the component of will and activities: people select to see things in formal methods, and the societal and traditional factors of these elections vary with time-period and location. Though they talk over the same subject, attitude differs from one person to another. Attitude is inherently a subjective issue. The way we see a particular matter may be different from another. This will create different notions and anticipation. In the event of Takaful, Muslims may know the basics of Takaful, but non-Muslims may have a mixed attitude or no knowledge about Takaful (Dowler et al., 2006). Maysami and Williams (2006) investigated the Muslim people's attitude of Takaful in Singapore. They found that there was a significant relationship between Takaful consciousness and the participants' religious beliefs about the attributes of the Takaful industries. Also, Akhter and Hussain (2012) surveyed 156 insurance clients in Pakistan, and they concluded that most of the participants are not aware of the notion of Takaful. Education was the only significant factor which can influence the level of attitude and consciousness on Takaful.

Mansor et al. (2015) found that Malaysian Muslim clients have the opportunity of choosing between Takaful and conventional insurance products. Also, subject to the form of Takaful product concept, Takaful is more preferred as it is Shari'ah compliance and compatible with the Islamic guidelines. Nevertheless, the idea of Takaful is unclear to many even to Muslims, due to inappropriate clarification for educating them in most of their secret benefits (Mansor et al., 2015). Moreover, Al Nemer (2015) conducted a study on knowledge and awareness of 420 participants of Takaful industries in Saudi Arabia and found that participants had lowlevel perceived information from Takaful operators which leads to poor knowledge on the fundamentals of Takaful. Moreover, the Takaful operators have to make additional efforts to teach their participants about their benefits and constraints in the Takaful fund. The destiny of the Takaful companies is reliant on appropriate knowledge of the business and interests of participants by other shareholders, including the clients, Takaful operators and the controllers.

\section{Conceptual Framework and Research Hypotheses}

Based on the literature review, the conceptual framework guided this study is presented in Figure 1. This framework emphasizes the decision on taking Takaful Retirement Annuity Plan (TRAP) by the consumers' as the dependent variable. Consumers' perceived value and knowledge on TRAP are shown as independent variables. The attitude of consumers' towards TRAP acts as a mediating variable. The framework depicts the relationships between the dependent variable and the independent variables, including the mediating variable as indicated by the arrow marks. 


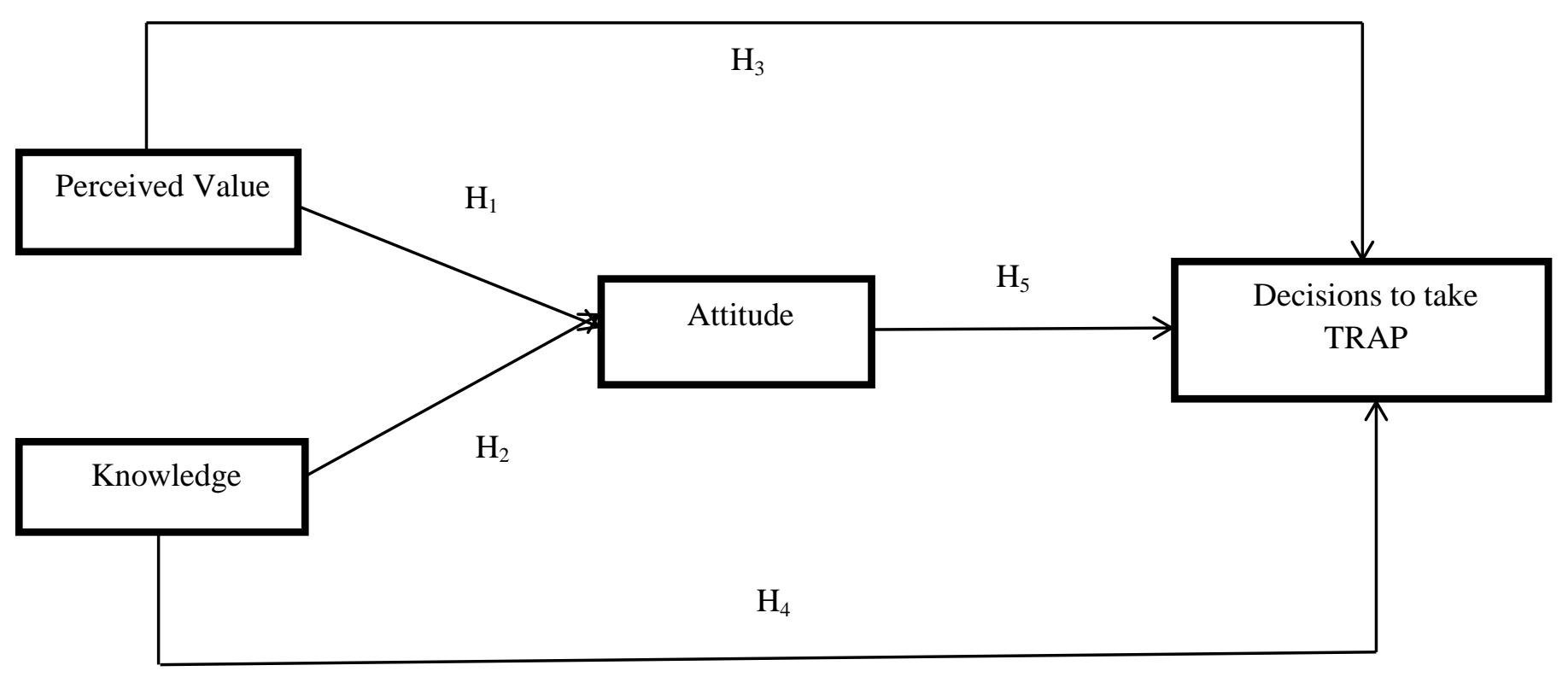

Figure 1: The conceptual framework of the Study

To achieve the objectives of this study, the following five major research hypotheses are formulated based on the evidence drawn from comprehensive literature reviews:

$\mathrm{H}_{1}$ : There is a positive and significant relationship exists between consumers' perceived value and attitude towards taking decisions on TRAP.

$\mathrm{H}_{2}$ : There is a positive and significant relationship exists between consumers' knowledge and attitude towards taking decisions on TRAP.

$\mathrm{H}_{3}$ : There is a positive and significant relationship exists between consumers' perceived value and decisions to take TRAP.

$\mathrm{H}_{4}$ : There is a positive and significant relationship exists between consumers' knowledge and decisions to take TRAP.

$\mathrm{H}_{5}$ : There is a positive and significant relationship exists between consumers' attitude and decisions to take TRAP.

\section{Methods}

This study used a quantitative research design. A field survey method has been employed for collecting relevant primary data from the selected sample representing the study population. The target population for this study consisted of the employees working in different corporate offices in Malaysia. The sample $(n=121)$ was selected from the staffs of International Islamic University Malaysia (IIUM) situated in the metropolitan capital (Kuala Lumpur and Selangor) area of Malaysia.

A set of close-ended structured questionnaires were distributed among the respondents. The surveys were randomly allocated to the staffs based on purposive sampling selection criteria due to time constraint. The survey consisted of two parts with twenty-three questions. Here, there are six questions used for the measurement of signified control variables in part A, such as gender, age, education, marital status, profession, monthly income and seventeen questions are used for the measurement of independent and dependent variables such as perceived value, knowledge, attitude and decisions to take Takaful Retirement Annuity Plan.

The researchers used five-point Likert type scale as measurement scale for questions 7-23, in part B ranging from 1 (strongly disagree) to 5 (strongly agree), where, the first six questions (demographic related) are used as close-ended questions. The research instrument (questionnaire) was tested for mean and standard deviation to see the difference between variables. For reliability, Cronbach's Alpha has been computed. Pearson Correlation test has been applied for finding correlations among the study variables (constructs) to identify the strength of relationships existing among the constructs. The regression analysis has been conducted to assess the nature of relationships existing among the constructs. 


\section{Data Analysis and Findings}

Initially, the questionnaires were given a hand to hand among the sample respondents. There are 121 completed responses received out of 150 distributed questionnaires. Hence, the response rate was approximately $80 \%$. Here, the average age of respondents was around 35.3 years, where S.D. $=12.13$. It is visible that there are $35.73 \%$ respondents had their under-graduation, most of them are male with $53.80 \%$ and female with $46.2 \%, 59.90 \%$ respondents are married, $62.30 \%$ of the respondents have an income ranging from 1000 to 1500 USD (S.D. = 1.28) per month.

\begin{tabular}{|c|c|c|c|c|c|c|c|c|c|c|c|c|c|}
\hline Sl. & Variables & Mean & STD. & 1 & 2 & 3 & 4 & 5 & 6 & 7 & 8 & 9 & 10 \\
\hline 1 & Gender & 1.84 & 0.7 & 1 & & & & & & & & & \\
\hline 2 & Age & 35.3 & 12.13 & 0.189 & 1 & & & & & & & & \\
\hline 3 & Marital Status & 1.42 & 0.7 & -0.188 & 0.05 & 1 & & & & & & & \\
\hline 4 & Profession & 2.72 & 0.68 & -0.035 & -0.12 & 0.289 & 1 & & & & & & \\
\hline 5 & Education & 2.19 & 1.78 & 0.066 & 0.088 & -0.57 & -0.135 & 1 & & & & & \\
\hline 6 & Monthly Income & 4 & 1.63 & 0.07 & 0.058 & 0.07 & $.567 * *$ & -0.157 & 1 & & & & \\
\hline 7 & Perceived Value & 3.59 & 1.44 & -0.149 & -0.09 & -0.087 & 0.049 & 0.047 & 0.019 & 1 & & & \\
\hline 8 & Knowledge & 3.68 & 1.37 & -0.008 & -0.08 & 0.265 & 0.057 & -0.338 & -0.08 & -0.19 & 1 & & \\
\hline 9 & Attitude & 3.34 & 0.76 & -0.152 & -0.1 & 0.078 & 0.27 & -0.551 & $.345^{*}$ & 0.288 & $.557 * *$ & 1 & \\
\hline 10 & TRAP & 3.66 & 1.43 & -0.135 & -0.89 & 0.144 & 0.273 & -0.498 & 0.147 & -0.13 & $.486 * *$ & $.518 * *$ & 1 \\
\hline \multicolumn{14}{|c|}{ Notes: ** Correlation is significant at the 0.01 level (2-tailed) } \\
\hline
\end{tabular}

For measurement scale, five-point Likert type scale were used for all the items ranging from $1=$ Strongly Disagree to $5=$ Strongly Agree (with $1=$ Strongly Disagree, $2=$ Disagree, $3=$ Neutral, $4=$ Agree, $5=$ Strongly Agree). There were three items used to measure the perceived value where the Cronbach's alpha coefficient was 0.83 . After that, five items were used to measure the knowledge where the Cronbach's alpha coefficient was 0.750 . Then, five items were used to measure the attitude where the Cronbach's alpha coefficient was 0.82 . Finally, four items were used to measure the decisions to take the Takaful Retirement Annuity Plan, where the Cronbach's alpha coefficient was 0.84 .

Our collected data were best fit to test the research objectives. In this study, we use the regression analysis to establish convergent validity following the suggestion of Anderson and Gerbing (1988). In this study, we try to know how all scale items used hypothesize factors expressively. The outcomes of this study delivered evidence of convergent validity for our measurement scale. Researchers used hierarchical linear regression to examine the hypothesis. Accordingly, in the first step researchers put control variables and include attitude as the dependent variable. Then we got a negative relationship between education and attitude $(\mathrm{B}=$ $\left.-.266^{* * *}, \mathrm{P}<.001\right)$. For investigating the hypothesis 1 and 2 , researchers put perceived value and knowledge as independent variables and attitude as the dependent variable. Based on table 2, we found a positive and significant relationship between perceived value and attitude $\left(B=0.233^{* *}, \mathrm{p}<.01\right)$. So, hypothesis 1 is entirely supportive. 
Table 2: Relationships between IVs and DV

\begin{tabular}{|c|c|c|c|c|c|c|}
\hline \multirow{2}{*}{ Sl. } & & \multicolumn{2}{|l|}{ Attitude } & \multicolumn{3}{|c|}{ Takaful Retirement Annuity Plan } \\
\hline & & Model 1 & Model 2 & Model 3 & Model 4 & Model 5 \\
\hline 1 & Gender & -0.172 & -0.141 & -0.248 & -0.269 & -0.186 \\
\hline 2 & Age & -0.007 & -0.006 & 0.005 & 0.009 & 0.009 \\
\hline 3 & Marital Status & -0.026 & -0.182 & -0.067 & -0.366 & -0.078 \\
\hline 4 & Profession & -0.223 & -0.172 & $.477 \dagger$ & $.467 \dagger$ & $.487 \dagger$ \\
\hline 5 & Education & $-.266 * * *$ & $-.288 * * *$ & $-.337 * * *$ & $-.203 * *$ & $-.288^{*}$ \\
\hline 6 & Monthly Income & $.244 \dagger$ & $0.264 * *$ & -0.039 & -0.078 & -0.166 \\
\hline 7 & Perceived Value & & $0.233 * *$ & & -0.073 & \\
\hline 8 & Knowledge & & $0.311 * * *$ & & $.368 * *$ & \\
\hline 9 & Attitude & & & & & $0.488 *$ \\
\hline $\mathrm{R}^{2}$ & & 0.356 & 0.677 & 0.249 & 0.207 & 0.378 \\
\hline Adj. $\mathrm{R}^{2}$ & & 0.271 & 0.586 & 0.163 & 0.487 & 0.224 \\
\hline $\mathrm{F}$ & & $4.152 * *$ & $8.665 * * *$ & $2.343 * *$ & $3.695 * *$ & $3.448 * *$ \\
\hline \multicolumn{7}{|c|}{ Note: $* \mathrm{p}<0.05, * * \mathrm{p}<0.01, * * * \mathrm{p}<0.001 ; \uparrow \mathrm{p}<.10$} \\
\hline
\end{tabular}

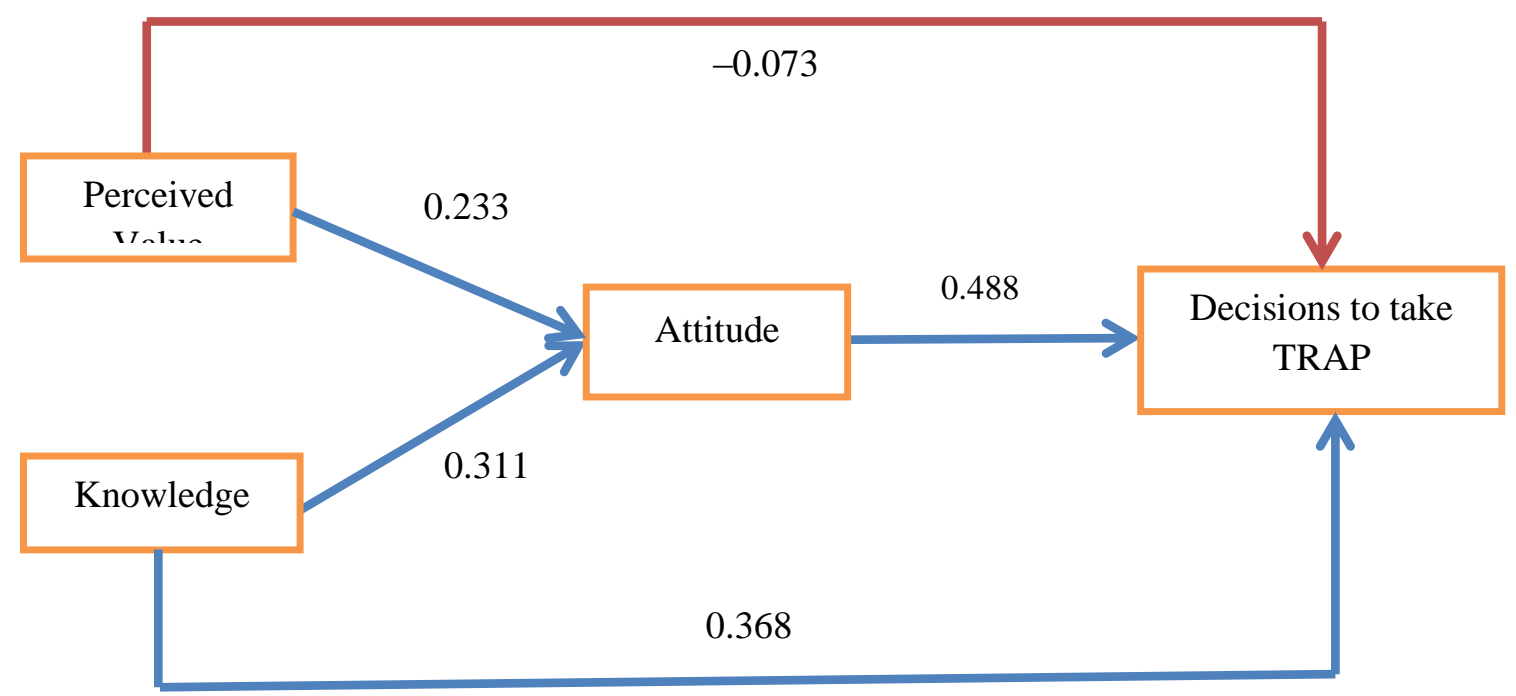

Figure 2: The hypothesis results

In our hypothesis 2 , we found a positive and significant relationship between knowledge and attitude $(\mathrm{B}=$ $\left.0.311^{* * *}, \mathrm{p}<.001\right)$. So, hypothesis 2 is also supportive. In hypothesis 3 , we found a negative and nonsignificant relationship between perceived value and Takaful Retirement Annuity Plan $(B=-0.073, p>.05)$. So, hypothesis 3 is not supported. In hypothesis 4, we found a positive and significant relationship between knowledge and Takaful Retirement Annuity Plan $\left(\mathrm{B}=0.368^{* *}, \mathrm{p}<.01\right)$. Therefore, hypothesis 4 is strongly supportive. In hypothesis 5 , we found a positive and significant relationship between attitude and Takaful Retirement Plan $\left(\mathrm{B}=0.488^{*}, \mathrm{p}<.05\right)$. So, hypothesis 5 is supportive.

\section{Discussions and Conclusion}

Annuities have for some time been seen as back-up money related plans during retirement age, and a way to diminish liquidity chance when an individual outlasts his/her advantages. The annuitant tries to make sure 
about consistent payouts during retirement age by exchanging fluid singular amounts as a byproduct of a progression of installments until he/she dies. The present investigation accentuates on past acts of Takaful retirement plans and research led on Takaful annuities in Malaysia. From the customs of Takaful annuity in Malaysia just as some examination yields led on the plausibility of the proposed item, there is an apparent incentive to evaluate the prescribed item and focus in on the issues preventing the advancement of Takaful annuities in Malaysia. The present research centers around clients due to past practices and contribution from industry players just as research discoveries on benefits in Malaysia.

The primary findings of the research have unveiled that there is a positive relationship between perceived value and attitude; knowledge and attitude; knowledge and Takaful Retirement Annuity Planning, and attitude and Takaful Retirement Planning which are shown by the blue shaded arrow in figure 2. Only the insignificant result found for the relationship between perceived value and Takaful Retirement Annuity Planning, indicated by the red colour arrow in figure 2. Preliminary findings suggest that the Takaful annuity product does not significantly affect by perceived values of people. Still, when it shows diversified investment portfolios means different attitudes to the people, it substantially affects the Takaful annuity plan both in terms of maturity and Islamic Shari'ah.

\section{References}

[1.] Akhter, W., \& Hussain, T. (2012). Takāful standards and customer perceptions affecting Takāful practices in Pakistan: A survey. International Journal of Islamic and Middle Eastern Finance and Management, 5(3), 229-240.

[2.] Ali, M. M., Hussain, L., \& Zai, F. H. (2018). Takaful Retirement Annuity Plan in Malaysia: A Proposed Model. Islam and Civilisational Renewal (ICR), 9(1), 27-47.

[3.] AlNemer, H. A. (2015). Participants' Knowledge and Educational Background about Takaful Products \& Services: An Empirical Study on Saudi Arabia. International Journal of Business, Economics and Law, 7(1).

[4.] Asmuni,N.H.\&Purcal,S.(2018).OnthestudyofMalaysia'sprivateannuity. Journal of Quality Measurement and Analysis JQMA, 14(1), 9-22.

[5.] Dowler, E., Green, J., Bauer, M., \& Gasperoni, G. (2006). Assessing public perception: issues and methods. Health hazard and public debate: lessons for risk communication from BSE/CJD saga. Geneva: World Health Organization, 40-60.

[6.] Htay, S. N. N., Shaharuddin, W. R., Zahirah, W. R., \& Amin, H. (2012). Practices of insurance operators in Malaysia: Conventional vs. Unconventional Life Insurance. Journal of Islamic Banking \& Finance, 29(3).

[7.] Ismail, F. (2017). Islamic pensions: developing takāful retirement products. Available at: www. menainsuranceceoclub.com/Article.aspx?id=13821.

[8.] Jaffer, S., Ismail, F., Noor, J., Unwin, L., \& Ajayi, D. (2010). Takaful (Islamic Insurance): Concept, Challenges, and Opportunities. Milliman Research Report.

[9.] Mansor, K. A., Masduki, R. M. N., Mohamad, M., Zulkarnain, N., \& Aziz, N. A. (2015). A Study on Factors Influencing Muslim's Consumers Preferences Towards Takaful Products In Malaysia. Romanian Statistical Review, 63(2),78-89.

[10.] Maysami, R. C., \& Williams, J. J. (2006). Evidence on the relationship between Takaful insurance and fundamental perception of Islamic principles. Applied Financial Economics Letters, 2(4),229232.

[11.] Mohamed, O. E. B., \& Alhabshi, S. O. (2015). Factors Influencing the Penetration Rate of Malaysian Takāful Industry from Takāful Managers' Perspective. International Journal of Excellence in Islamic Banking and Finance, 182(3080),1-13.

[12.] Rahman, Z. A., Yusof, R. M., \& Bakar, F. A. (2008). Family takaful: its role in social economic development and as a savings and investment instrument in Malaysia-an extension. Jurnal Syariah, 16(1), 89-105.

[13.] Sabirzyanov, R. \& Hashim, M. H. (2015). Takaful (Islamic Insurance), Risk Management and Maqasid Al-Sharī 'Ah. İslam Ekonomisi ve Finansi Dergisi, 1, 105-145.

[14.] Soualhi,Y.(2017).ChallengesofdevelopingatakāfulretirementannuityplaninMalaysia. International Journal of Islamic Finance, 9(1), 95-99.

ISRA 
[15.] Yusof, M. F., Ismail, W. Z. W., \& Naaim, A. K. M. (2011). Fundamenatals of Takaful. IBFIM, Kuala Lumpur. 